Абдрахманова Анастасия Александровна

кандидат экономических наук, доцент кафедры менеджмента и бизнес-аналитики Севастопольского государственного университета

\section{РЕАЛИЗАЦИЯ ИНДИВИДУАЛЬНОЙ ОБРАЗОВАТЕЛЬНО-КАРЬЕРНОЙ TРАЕКТОРИИ КАК ИНСТРУМЕНТ ФОРМИРОВАНИЯ КОНКУРЕНТОСПОСОБНОСТИ БУДУЩИХ СПЕЦИАЛИСТОВ}

Abdrakhmanova Anastasiya Alexandrovna

PhD in Economics, Associate Professor, Management and Business Analytics Department, Sevastopol State University

IMPLEMENTATION OF INDIVIDUAL EDUCATIONAL AND CAREER TRAJECTORIES AS A TOOL FOR DEVELOPING THE COMPETITIVENESS IN FUTURE SPECIALISTS

Аннотация:

Статья посвящена изучению специфики управления образовательно-карьерной траекторией студентов высшего учебного заведения с позиции формирования конкурентоспособности будущих специалистов на рынке труда. Выполнено исследование ведущих карьерных ориентаций, рассмотрены их особенности в зависимости от направления подготовки обучающихся вуза. Полученные результаты позволили автору осуществить группировку анализируемых карьерных ориентаций, а также формализовать векторы профессионального развития для каждой из описанных групп. На основании итогов кластерного анализа разработана классификация типов карьерных стратеаий в зависимости от качественного состава и степени выраженности ведущих карьерных ориентаций. Определены возможности для наиболее эффективной карьерной самореализации молодых людей, а также ее характерные черты. Предложенный подход обеспечивает решение комплекса вопросов, затрагивающих повышение уровня адаптации специалистов, в том числе молодежи, на рынке труда.

Ключевые слова:

конкурентоспособность, развитие, карьера, карьерная ориентация, стратегия, образовательная траектория, внеучебная траектория, карьерная траектория.

Развитие экономики на современном этапе можно охарактеризовать такими ключевыми трендами, как глобализация и ускорение, проявляющимися и в плоскости карьерной реализации молодежи. Одним из признаков ускорения ритма жизни можно считать раннюю профориентацию обучающихся в целях повышения эффективности управления последующей карьерой, что находит отражение как в аспекте принятия решения относительно вектора профессионального развития, так и в получении базовых навыков и компетенций путем раннего старта профессиональной деятельности. Такая ситуация обусловливает целесообразность карьерного самоопределения студентов в начале учебного процесса.

Анализ исследований в сфере проектирования индивидуальной карьерно-образовательной траектории позволил выделить следующие подходы:

- содержательный [1]: внимание авторов сфокусировано на технологии определения оптимального набора факультативных и элективных дисциплин в целях повышения удовлетворенности студента процессом и результатами обучения;

- личностно ориентированный [2]: направлен на разработку моделей адаптивного формирования образовательной траектории с учетом индивидуальных особенностей студентов; 
- компетентностный [3]: направлен на повышение конкурентоспособности путем приобретения узкопрофильных компетенций, представляющих профессиональный портрет высококлассного специалиста;

- «цифровой» [4]: ведущими инструментами выступают информационные системы, позволяющие реализовать дистанционные технологии и методики непрерывного образования в высшей школе.

Несмотря на глубокую проработанность вопроса, аспект управления карьерным развитием студентов в тренде индивидуализации образования остается недостаточно раскрытым. В статье предлагается комплексный подход, позволяющий решить задачи индивидуализации образования путем формирования профессионально-образовательной траектории на основании карьерной стратегии.

В целях выявления особенностей реализации механизма формирования карьерно-образовательной траектории как инструмента развития конкурентоспособности будущих специалистов проведено исследование, выполненное на базе опросника Э. Шейна «Якоря карьеры» [5]. Опросник включает 41 утверждение, которое респондент оценивает, исходя из собственного видения. Представленные утверждения позволяют определить ведущие карьерные ориентации, к которым относятся профессиональная компетентность, менеджмент, автономия, стабильность места работы, стабильность места жительства, служение, вызов, интеграция стилей жизни и предпринимательство. Цель опроса - установление структуры карьерных ориентаций личности и доминирующей ориентации в выборе карьеры, а также формализация предпочтений человека в выборе профессионального пути и построении карьеры.

Опрос реализован в системе дистанционного обучения (Moodle) Севастопольского государственного университета в рамках изучения курса «Технологии личностного развития», включенного в программу первого года обучения практически по всем направлениям подготовки. $\mathrm{Pe-}$ спондентами выступили 126 человек, отобранных по критерию наличия заинтересованности в разработке и реализации карьерной траектории развития, в частности студентов, планирующих развивать карьерно-образовательную траекторию путем освоения факультативной дисциплины «Стартап карьеры». В качестве ограничений исследования можно обозначить то, что опрос реализован исключительно среди студентов первого курса, а образ индивидуальной карьерной траектории приобретает более четкие контуры по мере профессионального становления будущего специалиста, что свидетельствует о целесообразности повторных исследований на более поздних этапах обучения в вузе.

На первом этапе получено подтверждение наличия существенных различий между карьерными ориентациями обучающихся разных направлений подготовки, что свидетельствует о необходимости формализации типовых карьерных стратегий на ранних этапах обучения.

Одним из инструментов классификации данных является кластерный анализ (иерархический метод). На рисунке 1 представлена вертикальная дендрограмма карьерных ориентаций. $\mathrm{Pe}-$ зультаты кластерного анализа свидетельствуют о том, что «близкими» являются следующие профессиональные ориентации.

- «Менеджмент», «Вызов» и «Предпринимательство». Человеку, сфокусированному на данных видах карьерных ориентаций, следует выстраивать личный стратегический план с целевым продвижением в направлении руководящих должностей, а также развиваться в сфере реализации индивидуальных предпринимательских проектов.

- «Интеграция стилей жизни» и «Автономия». При таком фокусе ведущих ориентаций на первый план выходят проблемы комфорта, ведения привычного образа жизни. Индивид выбирает вакансию с возможностью сохранения баланса между личной и профессиональной жизнью, а также отсутствием жестких организационных рамок. Вопрос карьерного продвижения вторичен, возможности для получения высоких должностей имеются в исключительных случаях, при соблюдении указанных условий.

- «Интеграция стилей жизни», «Автономия», «Стабильность места работы» и «Служение». Такая комбинация ведущих карьерных ориентаций предполагает стабильность в выборе области и места профессиональной деятельности с учетом соблюдения условий личного комфорта. Важным аспектом выступает осознание собственной значимости, полезности результатов профессиональной деятельности. 


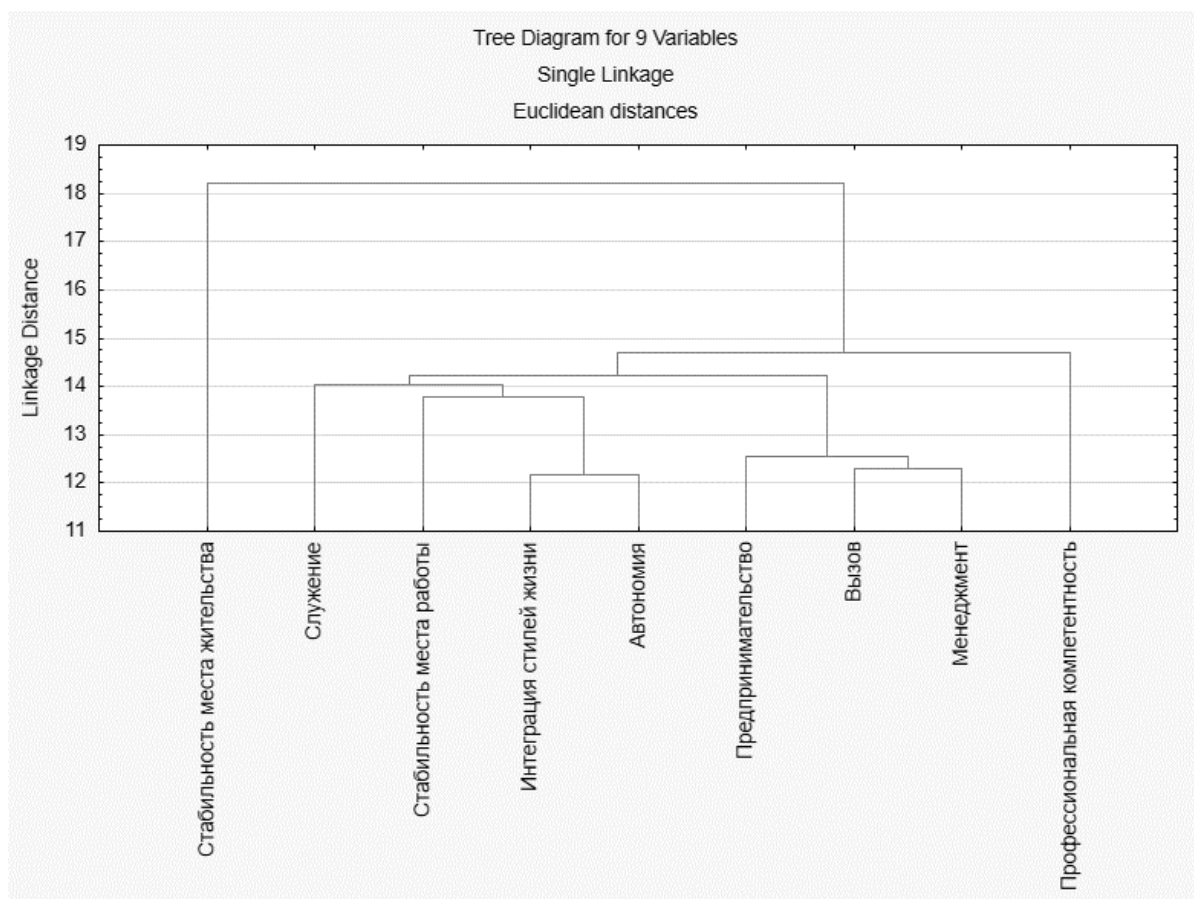

Рисунок 1 - Вертикальная дендрограмма карьерных ориентаций

Если рассматривать более укрупненно, все комбинации ведущих карьерных ориентаций респондентов можно разделить на две группы, которые позволят сформировать следующие кластеры:

1) «Менеджмент», «Вызов», «Предпринимательство», «Профессиональная компетенция»;

2) «Интеграция стилей жизни» «Автономия», «Стабильность места работы», «Служение», «Стабильность места жительства».

На втором шаге выполнена кластеризация методом К-средних. На рисунке 2 представлены средние значения показателей степени выраженности карьерных ориентаций у респондентов, распределенных по соответствующим кластерам.

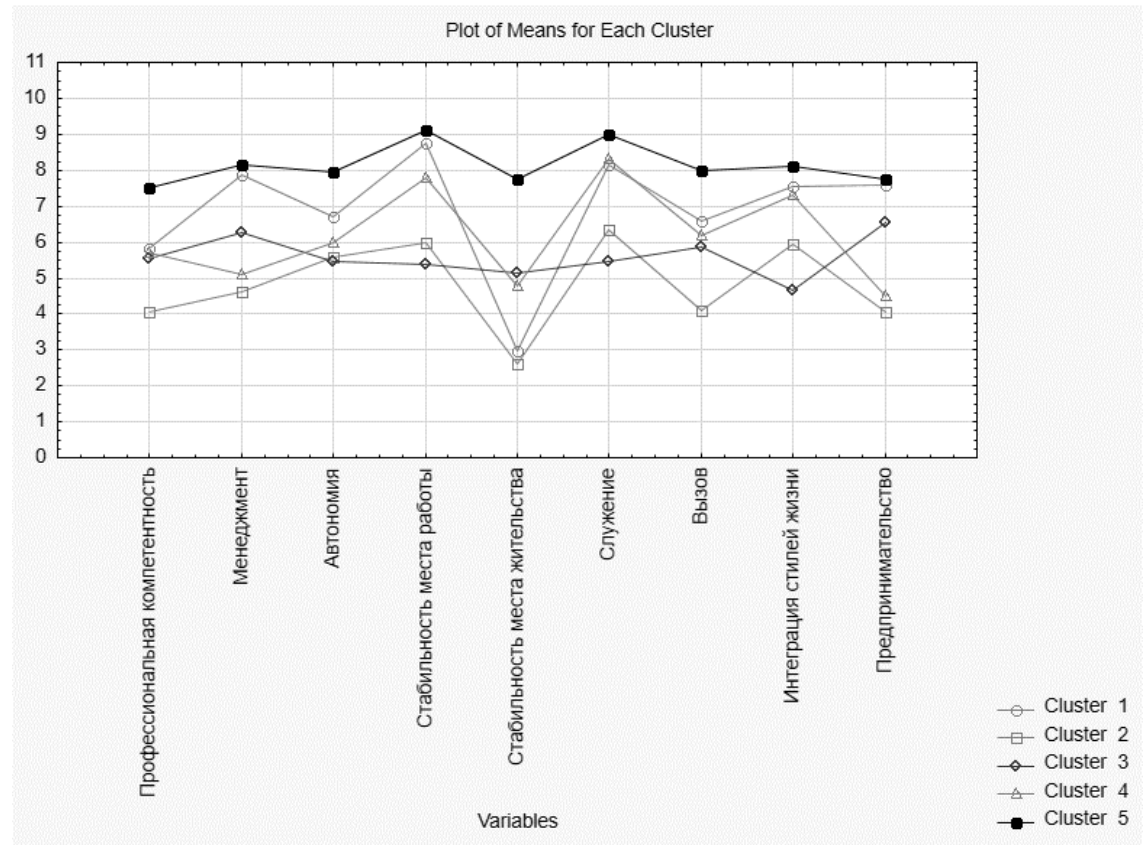

Рисунок 2 - Кластеры карьерных ориентаций

Расчетные средние значения соответствующих параметров профессиональных ориентаций позволили формализовать выделенные кластеры как следующие варианты карьерных стратегий респондентов. 
- «Организатор» (кластер 1) - ориентирован на продвижение по карьерной лестнице, стремится занять руководящий пост с возможностью непосредственного контакта с подчиненными с помощью интегрирования усилий коллектива для достижения желаемого результата.

- «Исполнитель» (кластер 2) - стабильный сотрудник, нацеленный на соблюдение баланса между профрессиональной и личной самореализацией. Ориентирован на базовый уровень профессиональной компетентности. Высокие карьерные амбиции отсутствуют. Среди профессиональных ценностей превалируют ответственность, полезность, стабильность, защищенность, привычный образ жизни.

- «Стартапер» (кластер 3) - индивид, стремящийся к решению задач повышенной сложности в условиях конкурентной борьбы. Потенциально готов к адекватному восприятию и эффективной деятельности в рамках турбулентной внешней среды, не ищет стабильности. Стремится к осуществлению предпринимательской деятельности. Способен принимать вызовы и руководить коллективом.

- «Специалист» (кластер 4) - стабильный сотрудник, обладающий достаточным уровнем профессиональной компетентности, ориентированный на поиск баланса между профессиональной и личной самореализацией. В случае дальнейшего укрепления карьерных ориентаций, связанных с повышением уровня профессиональной компетентности, реализацией автономного образа жизни, а также стремления к вызову, возможно продвижение по карьерной лестнице с получением соответствующего статуса.

- «Лидер» (кластер 5) - респонденты, продемонстрировавшие наибольшую силу мотивации на профессиональную состоятельность. При этом в качестве ведущих карьерных ориентаций можно выделить «служение» и «стабильность места работы». Данный кластер составляют респонденты с высоким уровнем карьерных амбиций. В случае подкрепления последних соответствующими профессиональными компетенциями, а также навыками данная категория имеет высокие шансы на эффрективное карьерное продвижение.

Формализованные варианты карьерных стратегий представляют собой основу для последующей реализации образовательно-карьерной траектории, воплощаемой на этапе обучения в вузе с учетом индивидуальных особенностей студента несколькими путями: посредством формирования релевантного пула дисциплин по выбору; проработкой карьерной траектории с помощью получения первичного профессионального опыта в процессе прохождения соответствующих практик; участием во внеучебной деятельности университета в целях приобретения метакомпетенций.

Таким образом, разработка и реализация индивидуальной образовательно-карьерной траектории могут выступать, с одной стороны, предиктором эффективности трудоустройства выпускников вуза, с другой - инструментом нивелирования рисков низкого уровня профильной занятости выпускников, а также в целом оптимизировать процесс формирования кадрового потенциала региона. Предложенный подход дает возможность решить комплекс вопросов, касающихся повышения уровня адаптации специалистов, в том числе молодежи, на рынке труда при продвижении на новый технологический уровень, что приобретает особую актуальность в условиях перехода к новым технологическим решениям индустрии 4.0.

Область практической реализации результатов исследования заключается в возможностях применения индивидуального подхода к фрормированию образовательно-карьерной траектории студента путем выявления релевантных карьерных стратегий. Предложенная методика позволит не только увеличить эффективность индивидуальной траектории путем создания оптимального пула дисциплин по выбору, но и усовершенствовать этот процесс в части определения и обеспечения ключевых условий для получения профессиональных компетенций (место прохождения практики, задачи, роль и т. д.) для последующего формирования метакомпетенций. С помощью представленной технологии можно повысить качество реализации образовательного процесса, а также обеспечить конкурентоспособность будущих специалистов на соответствующем рынке труда, что в итоге окажет существенное влияние на качественные характеристики кадрового потенциала региона и выступит драйвером его экономического развития.

\section{Ссылки:}

1. Герцен С.М., Сухарева О.Э., Скороходова Л.В. Индивидуальные образовательные траектории как инновационная технология развития высшего образования // Высшее образование сегодня. 2019. № 10. С. 57-61. http://dx.doi.org/10.25586/RNU.HET.19.10.P.57.

2. Аверченко В.И., Кондратенко С.В., Спасенников В.В. Модель адаптивного формирования образовательной траектории с учетом индивидуальных особенностей студентов // Вестник Брянского государственного технического университета. 2017. № 8 (61). С. 34-40. https://doi.org/10.12737/article_5a3779fc6868e7.67655158 ; Вайнштейн Ю.В., Есин Р.В., Цибульский Г.М. Адаптивная модель построения индивидуальных образовательных траекторий при реа- 
лизации смешанного обучения // Информатика и образование. 2017. № 2 (281). С. $83-86$; Мельникова Н.Н., Щелокова Е.Г. Карьерная направленность: векторная модель диагностики и интерпретации // European Social Science Journal. 2012. № 2 (18). C. 270-277.

3. Гладышев А.А., Митрофанов Е.И., Клетнева А.А. Моделирование индивидуальной образовательной траектории студентов вуза на основе компетентностного подхода // Физическая культура: воспитание, образование, тренировка. 2014 . № 2. С. 62-66 ; Огнев А.С., Лихачева Э.В. Построение индивидуальных образовательных траекторий, ориентированных на будущий успех студентов // Гуманитарные ведомости ТГПУ им. Л.Н. Толстого. 2014. № 3 (11). С. 111-115.

4. Пожаркова И.Н., Носкова Е.Е., Трояк Е.Ю. Формирование индивидуальной образовательной траектории как компонента практико-ориентированной среды обучения // Педагогический имидж. 2018. № 3 (40). С. 179-192. https://doi.org/10.32343/2409-5052-2018-11-3-179-192.

5. Почебут Л.Г., Чикер В.А. Организационная социальная психология : учебное пособие. СПб., 2002.297 с.

\section{References:}

Averchenko, VI, Kondratenko, SV \& Spasennikov, VV 2017, 'Model of Adaptive Formation of Educational Path Taking into Account Students' Individual Peculiarities', Vestnik Brjanskogo gosudarstvennogo tehnicheskogo universiteta, no. 8 (61), pp. 34-40, https://doi.org/10.12737/article_5a3779fc6868e7.67655158, (in Russian).

Gladyshev, AA, Mitrofanov, El \& Kletneva, AA 2014, 'Modeling the Individual Educational Trajectory of University Students on the Competency-based Approach', Fizicheskaja kultura: vospitanie, obrazovanie, trenirovka, no. 2, pp. 62-66, (in Russian).

Herzen, SM, Sukhareva, OE \& Skorokhodova, LV 2019, 'Individual Educational Trajectories as an Innovative Technology for the Development of Higher Education', Vysshee obrazovanie segodnja, no. 10, pp. 57-61, http://dx.doi.org/10.25586/RNU.HET.19.10.P.57, (in Russian).

Melnikova, NN \& Shchelokova, EG 2012, 'Career Focus: Vector Model of Diagnosis and Interpretation', European Social Science Journal, no. 2 (18), pp. 270-277, (in Russian).

Ognev, AS \& Likhacheva, EV 2014, 'Construction of Individual Educational Paths Oriented on the Future Success of Students', Gumanitarnye vedomosti TGPU im. L.N. Tolstogo, no. 3 (11), pp. 111-115, (in Russian).

Pochebut, LG \& Chiker, VA 2002, Organizational Social Psychology: A Training Manual, St. Petersburg, 297 p., (in Russian). Pozharkova, IN, Noskova, EE \& Troyak, EYu 2018, 'Formation of Individual Educational Trajectory as a Component of Practiceoriented Learning Environment', Pedagogicheskij imidzh, no. 3 (40), pp. 179-192, https://doi.org/10.32343/2409-5052-2018-11-3-179192, (in Russian).

Weinstein, YuV, Esin, RV \& Tsibulsky, GM 2017, 'An Adaptive Model for Constructing Individual Educational Paths in the Implementation of Blended Learning', Informatika i obrazovanie, no. 2 (281), pp. 83-86, (in Russian).

Редактор: Тюлюкова Мария Олеговна Переводчик: Ездина София Александровна 